\title{
THE LANDSCAPE OF ONE BREAST: EMPOWERING BREAST CANCER SURVIVORS THROUGH DEVELOPING A TRANSDISCIPLINARY INTERVENTION FRAMEWORK IN A JIANGMEN BREAST CANCER HOSPITAL IN CHINA
}

\author{
Yuk Yee Lee Karen ${ }^{1}, \&$ Kin Yin $\mathrm{Li}^{2}$ \\ ${ }^{1}$ School of Social Work, Gratia Christian College /Assistant Professor (Hong Kong) \\ ${ }^{2}$ School of Social Work, Gratia Christian College / HEAD (Hong Kong)
}

\begin{abstract}
Breast cancer is a major concern in women's health in Mainland China. Literatures demonstrates that women with breast cancer (WBC) need to pay much effort into resisting stigma and the impact of treatment side-effects; they suffer from overwhelming consequences due to bodily disfigurement and all these experiences will be unbeneficial for their mental and sexual health. However, related studies in this area are rare in China. The objectives of this study are 1) To understand WBC's treatment experiences, 2) To understand what kinds of support should be contained in a transdisciplinary intervention framework (TIP) for Chinese WBC through the lens that is sensitive to gender, societal, cultural and practical experience. In this study, the feminist participatory action research (FPAR) approach containing the four cyclical processes of action research was adopted. WBC's stories were collected through oral history, group materials such as drawings, theme songs, poetry, handicraft, storytelling, and public speech content; research team members and peer counselors were involved in the development of the model. This study revealed that WBC faces difficulties returning to the job market and discrimination, oppression and gender stereotypes are commonly found in the whole treatment process. WBC suffered from structural stigma, public stigma, and self-stigma. The research findings revealed that forming a critical timeline for intervention is essential, including stage 1: Stage of suspected breast cancer (SS), stage 2: Stage of diagnosis (SD), stage 3: Stage of treatment and prognosis (ST), and stage 4: Stage of rehabilitation and integration (SRI). Risk factors for coping with breast cancer are treatment side effects, changes to body image, fear of being stigmatized both in social networks and the job market, and lack of personal care during hospitalization. Protective factors for coping with breast cancer are the support of health professionals, spouses, and peers with the same experience, enhancing coping strategies, and reduction of symptom distress; all these are crucial to enhance resistance when fighting breast cancer. Benefit finding is crucial for WBC to rebuild their self-respect and identity. Collaboration is essential between 1) Health and medical care, 2) Medical social work, 3) Peer counselor network, and 4) self-help organization to form the TIF for quality care. The research findings are crucial for China Health Bureau to develop medical social services through a lens that is sensitive to gender, societal, cultural, and practical experiences of breast cancer survivors and their families.
\end{abstract}

Keywords: Gender sensitive, women with breast cancer, transdisciplinary intervention framework, empowerment, feminist participatory action research.

\section{Background to the study}

Like other developing countries, for cancer patients in Mainland China "cancer" is not just a discourse regarded as a medical problem, they will be suffering from financial, social, psychological, and emotional problems as well. WBCs are suffering from psychological stress, self-stigma, and social exclusion. Wang (2014) reported that WBC received less social support and that at least one-third of WBCs in China suffer from higher psychological distress. Social support has also been connected with the quality of life of patients with breast cancer. Higher levels of social support have been associated with better adjustment for WBC (Simpson, Carlson, Beck, \& Patten, 2002). The impact of bodily disfigurement on breast cancer survivors' experiences of change in personal and sexual relationships. Compared to Israeli husbands, Chinese husbands were also more dissatisfied with their sexual relationships and marital adjustment after their wives' breast cancer experience (Woloski-Wruble \& Kadmon, 2002). According to a Consultant Medical Officer of breast cancer ward in JMCHCH, breast cancer doctors tend not to maximize the rights of breast cancer patients in choosing whether to have 
breast reconstruction or a mastectomy. Owing to no formal helping profession, such as medical social workers and clinical psychologists for breast cancer patients or well-organized patient self-help organizations in Mainland China, there is an urge for more researchers in this area to advocate more appropriate and prompt medical care and social services for breast cancer patients and their families. Based on the above discussion, the objectives of this research are: 1. What are the Chinese WBC's treatment experiences, resistance to problems, meanings of their symptoms? 2. What kinds of services or support should be contained in a transdisciplinary intervention framework for Chinese WBC through a lens that is sensitive to gender, societal, cultural, and practical experiences of WBC for policymakers in a Breast Cancer Hospital in China to modify their health care support service for WBC?

\section{Research design and methods}

Health care researchers of Mainland China are still dominated by logical positivism (Yu \& Liu, 2008) and its successors of medical hegemonism. This study was highly influenced by the concept of "an ethics of Care Epistemology" (Kim, 2006). The knowledge construction should include the voice of the patients and their carer. How does the medical system disregard the treatment process, construct the powerless, oppress or cause inferiority of the woman through socialization or distribution of power and privilege? In view of this, the feminist perspective is considered the most appropriate lens to understand the oppressed voices of WBC in medical settings in Mainland China. Therefore, this study was adopted the Feminist Participatory Action Research. This FPAR generally includes a spiral process of (a) planning for change, (b) acting and observing, (c) reflecting on the processes and consequences, and then (d) beginning the process again through re-planning (Mertler, 2017). As in many action research projects, these stages are not always linear and often overlap.

\subsection{Sampling and data collection}

The research project will cooperate with the Jiangmen Maternity and Child Health Care Hospital (JMCHCH). Six core action team members were recruited, 14 Participants and a carer (eligible women aged 18 or above) were outpatients with distress in receiving chemotherapy or radiation at JMCHCH. They were identified and invited through purposive sampling and referred by the hospital. As PAR is committed to anti-oppression, empowerment and takes the role of change. The results of action research are intended to directly benefit the situation of ordinary people and the collaborator, research findings are supposed to encourage interaction and self-reflection. For collecting the data, in action Stage I using oral history and participatory observation, and group materials such as expressive art products, drawings, themes songs, letter, poetry, handicraft as data in Stage II, storytelling and public speech content will be the data in action Stages III and IV. Reflection meetings notes in all action stages as a very important data.

\section{Finding and discussion}

\subsection{Experiences of WBC at every treatment stage}

We began our journey of oral history in early 2018 , following discussion with the action team members, it was classified into the treatment stages could be divided into four stages. For stage 1: Stage of suspected breast cancer (SS), in the interview, the WBCs felt very stressed and helpless in this stage but both formal and informal networks are rare. It is vital if he health professionals' positive attitudes having a great influence on the willingness of the WBC to receive cancer treatment. WBCs and their families were well-informed about their illness, its treatment and prognosis, which could reduce refusal of cancer treatment. For stage 2: Stage of diagnosis (SD), the biggest impact for WBCs and their families is harmful to their lives, followed by the impact on livelihoods and their body image. Although compared with the other two factors, we found a negative impact on body image to be comparatively low. Nevertheless, body image is one of the biggest barriers to receive the breast cancer removal surgery of WBCs. At stage 3: Stage of treatment and prognosis (ST), the Risk factors for coping of the cancer is suffering from distressing and traumatizing treatment side effects, fear of being stigmatized/discriminated about the state of their health and the changes to their bodily appearance as well as lacking family personal care during hospitalization. For the Protective factors for coping, the caring responsibility of elderly parents and children would increase the resilience and optimistic thinking of WBC. Social support of spouse and peer support from those with the same cancer experience was greatly helpful. Support of health professionals, we found attitudes and communication skills crucial for supporting WBC to continue with cancer treatment. Stage 4: Stage of rehabilitation and integration (SRI), In this research, among the interviewees, were facing difficulties returning to the job market and social inclusion, they concerned about their livelihoods in the future and fears of finding employment, they worried about not finding a job and worry about their livelihoods was more important than the illness itself. 


\subsection{Relationships}

On Changing in their Relationships with Others and community after Surgery, the current study supports previous literature in that these women experience changes in the whole of their life (Yusuf et al., 2013); from caregiver to care receiver; changes in their social role; changes in body and personal image, changes in personal relationships; either positive or negative. In this research revealed that breast cancer in Mainland China is perceived as a shameful disease. The dominant pathologizing and cultural discourses in Mainland China constructs them as "Bringing bad luck and disgrace to the family and village' and thus they are treated with negative stigmatizing attitudes. For WBC who choose to deceive their children until their death, only revealing the fact that their parents died of cancer at this time; making it difficult for children to accept that their parents died of cancer. Many children were not allowed or informed to see the "last face" of their parents, the right to grief should be advocated.

\subsection{Body image}

On Changing in body image, according to Schilder (1950), body image includes psychological, physical and social dimensions (Yang, 2003). We will examine it by using scars (body), self-concept (psychology), intimate sexual (social) contacts with WBC and consider how society understands how breast-conserving surgery may lead to barriers in social interaction and by understanding the changes in the psychological and physical status of women with cancer and their experience of gender issues.

3.3.1. Physical level - mastectomy scar. From the interviews, we found that seeing wounds is a very difficult moment for WBC. Some women are even more afraid of family members and even their husbands seeing or touching their wounds:

"I dared not look at the wound even when I was in the bathroom alone. It was quite disgusting indeed as part of the breast was removed....there was a bunch of things. " (Ah Xiu)

3.3.2. Psychological level - self-identity. WBC commonly avoid looking in the mirror and experience common sentiments including decreased self-worth and attractiveness and feeling deformed. WBC who had a mastectomy commonly has doubts about whether they are "real women":

"Without the breasts, a woman seemed as unlike a woman. ... When going to swim or hot springs in the future, it would be so ugly/odd if there is no breast on one side." (Ah Xiu)

3.3.3. Social level - intimate relationships. Decreased or lack of sexual desire after cancer treatment was a common problem for WBC couples:

"I did not think about having sex. Of course, he would have the thought (having sex) after abstinence for quite a while." (Ah Xiu)

From the stories, it reflected that WBCs' changes to their sexual identity was noticeable in the Chinese society. Doctor did not aware the importunateness to explain to breast cancer patients their rights to breast-conservation and non-breast conservation, as well as the related physically consequences of this operation, this is obviously further exploitation of the rights of women with breast cancer.

\subsection{Beneficial findings of breast cancer survivors through the peer support network}

WBC also benefitted from their fight with cancer and its empowering process, which increased their "individual sense of control, as well as enhancing positive coping and well-being" (Stang \& Mittelmark, 2009). However, the benefit finding of WBC is seldom explored in Chinese research. In current study, through the empowering peer-support group which is an effective way to facilitate WBC to be transformed as peer counselors. One of the peer counselors, Ah Xia's changes have been summarized in the following. They are:

1. Improvements in social relations- "Accompanied by a few good friends (with same cancer experience) to go out for a walk, sit down to take rest and chat."

2. A greater appreciation for life- "I think that I'm different, I'm more optimistic."

3. A changed sense of priorities- "I feel less burdened to view things and work now and things and work are not so important."

4. Self-love- "I feel it's a new me, I'll treat myself good and to love myself more."

5. Beneficial spiritual changes- "I think I am free... (now)".

6. Sense of control- "Now I can say that I am free and there is nothing to worry about, I like to have fun and enjoy life whenever I want."

Based on the powerful empowering experiences from the peer support network, the action team has proposed to conduct study tour in Hong Kong to learn peer support network, other supportive services for WBCs and study the intervention framework in the Breast Cancer Ward. They hoped to find out that what kinds of support would be helpful for WBC to better reintegrate them into the community, ease their embarrassment and self-stigmatize identity? 


\subsection{Construction of the Transdisciplinary intervention framework (TIF) using the participatory approach}

Under collaboration with peer counselors, breast cancer doctor, psychologist, front-line social worker and social work teacher, researcher and the consultant by using the participatory approach, reflection in action. Every member has raised their ideas on service design and service-workflow, they also highlighted the urgency and feasibility to form the peer support system in Jiangmen. The TIF workflow was subsequently constructed and the crucial findings of the Role \& functions of different parties are summarized in Table 1.

Table 1. Role \& functions of different parties.

\begin{tabular}{|c|c|c|}
\hline \multicolumn{3}{|c|}{ Role \& functions of the Health and medical care domains (doctors and nurses) } \\
\hline SS & Gatekeeper & $\begin{array}{l}\text { 1.Preliminary medical consultation, 2.Make referral to the Medical Social } \\
\text { Service Unit (MSSU) based on their willingness. }\end{array}$ \\
\hline SD & Educator & $\begin{array}{l}\text { Well-informed and explain the treatment plan, side effects and opportunities } \\
\text { for cure for WBCs and family members. }\end{array}$ \\
\hline ST & Therapist & $\begin{array}{l}\text { 1.Standardized caring service, 2.On-going explanation of illness and its } \\
\text { treatment plan, 3. Refer WBCs in need to MSSU. }\end{array}$ \\
\hline SRI & $\begin{array}{l}\text { Enabler and } \\
\text { Advocator }\end{array}$ & $\begin{array}{l}\text { 1.Community education, 2.Advocacy e.g. Reform of the MSSU in BC Ward, } \\
\text { 3.Maximize the WBCs' rights in making medical decision. }\end{array}$ \\
\hline \multicolumn{3}{|c|}{$\begin{array}{l}\text { Roles \& functions of the Medical social work domains - social worker and clinical/counseling } \\
\text { psychologist }\end{array}$} \\
\hline SS & Broker & $\begin{array}{l}\text { 1.Emotional supported, 2.Refer to welfare unit and/or Family and Patient } \\
\text { Resource Centers(FPRC). }\end{array}$ \\
\hline SD & Accessor & Assess the resources of the WBC \\
\hline ST & $\begin{array}{l}\text { Case manager, } \\
\text { Broker and } \\
\text { Therapist }\end{array}$ & $\begin{array}{l}\text { 1.Provide case management (Encourage patients to continue treatment, provide } \\
\text { the nonhospital-based home-help service for the WBCs in need), 2.Provide } \\
\text { support to peer counselors, 3.Sustain the WBC's social support (e.g., home } \\
\text { visit) for WBCs, 4.Carer support, 5.Refer the rehabilitation resources, } 6 \text {. } \\
\text { Therapeutic intervention (e.g. Sexual and hospice care. etc.) }\end{array}$ \\
\hline SRI & $\begin{array}{l}\text { Enabler, } \\
\text { Advocator, } \\
\text { Advisor, organizer } \\
\text { and trainer }\end{array}$ & $\begin{array}{l}\text { 1.Nurture the peer support network and the FPRC, 2.Provide carer support, } 3 \text {. } \\
\text { Facilitate the community integration of the WBCs, } 4 \text {.Regularly organize } \\
\text { community education to public, e.g. Anti-discrimination education, } \\
\text { Employment opportunities for WBCs, Maximize the rights of WBCs, Provide } \\
\text { illness information, Side effect's management, Symptoms management and its } \\
\text { prevention and recurrence. }\end{array}$ \\
\hline \multicolumn{3}{|c|}{ Roles \& functions of the Peer counselor network - peer counselor } \\
\hline SS & Broker & 1.Encourage the WBCs to receive treatment, 2.Provide medical resources \\
\hline $\mathrm{SD}$ & $\begin{array}{l}\text { Accompanying } \\
\text { person }\end{array}$ & $\begin{array}{l}\text { 1.Pair-up peer counselor support network, 2. Share treatment experience in } \\
\text { fighting cancer, 3.Provide emotional support and induce hope to the WBCs. }\end{array}$ \\
\hline ST & $\begin{array}{l}\text { Educator and } \\
\text { supporter }\end{array}$ & $\begin{array}{l}\text { 1.Share health care or healthy diet's information, } 2 \text {. Share the road of fighting } \\
\text { breast cancer, 3.Encourage the WBCs to maintain social support. }\end{array}$ \\
\hline SRI & $\begin{array}{l}\text { Accompanying } \\
\text { person }\end{array}$ & $\begin{array}{l}\text { Support and encourage breast cancer survivors to become peer counselors to } \\
\text { help new breast cancer patients in fighting cancer. }\end{array}$ \\
\hline \multicolumn{3}{|c|}{ Roles \& functions of the self-help organization } \\
\hline SS & Broker & Linking the care and health resources \\
\hline $\mathrm{SD}$ & $\begin{array}{l}\text { Accompanying } \\
\text { person }\end{array}$ & $\begin{array}{l}\text { 1.On-going emotional support, 2. Report the situation of the WBCs to MSSU } \\
\text { if any crisis }\end{array}$ \\
\hline ST & Educator & Provide stress management actives to family members, carer and WBCs \\
\hline SRI & $\begin{array}{l}\text { Advocator and } \\
\text { organizer }\end{array}$ & $\begin{array}{l}\text { 1.Organize support service, e.g., Run the free Prosthesis Bra or Wig } \\
\text { Programme, 2. Organize the consciousness-raising education program, such as } \\
\text { gender and anti-discrimination educational program. 3. Advocacy, e.g. the } \\
\text { rights of WBCs in making medical decision. }\end{array}$ \\
\hline
\end{tabular}

*Stage of suspected of having breast cancer (SS), 2. Stage of diagnosis (SD), stage of treatment and prognosis (ST), and the stage of rehabilitation and integration (SRI). *

During the research process, our team members had different views and understandings on what transdisciplinary, multidisciplinary as well as interdisciplinary approaches were. This is why we adopted the TIF because it is neither a multidisciplinary nor interdisciplinary nor solely an intervention framework. The action team members considered that the needs of WBC in every treatment stage, which involved different professionals, family systems and health care systems. All systems had a great influence on breast cancer patients and their families to reduce the stigma and discrimination, to overcome the 
psychological hardship and/or social problems. These systems are crucial for WBC to better re-integrated into their communities. Such consideration directed our action team to reflect that the "Transdisciplinary" approach should be promoted in medical social service settings in Mainland China.

\section{Conclusion}

In current research, we found that all stages of treatment, such as pre-treatment, diagnosis, and treatment (surgery, chemotherapy) as well as rehabilitation lack gender-centeredness in every treatment stage in hospitals in China. Caring is essential to the experience of WBC. The concepts of care and responsibility are primary to Chinese women's construction of their moral domain (Gilligan, 1982) as demonstrated by the notion that women are the primary caregivers in the home, caring for children and other family members, such as the elderly (Walker \& Thompson, 1983). It was inspiring that this current study revealed caring duties as one of the protective factors for WBC to continue treatment and fight cancer. When "caregivers" were very sick, who can replace their role in the family? These stories of WBCs revealed that in Chinese culture they do not allow their children to get involved in their treatment process and caring duties even when WBC faces death in the terminal stage of cancer. Do the children of WBC and their relatives have the right to grief (bereavement counseling for WBC's children) and how can they get the children of WBC involved; this could be one arguable issue for providing counseling for a person who is dying because it is important to be able to say goodbye to their beloved which is crucial to health grief. Grief is a normal and natural response to loss and we often expect to grieve the death of a family member. These WBS's stories revealed that the dominant cultural conception of breast cancer in Mainland China is "shameful", such discrimination is unspoken, the suffering is wounded not just in the body, the breast scar, but in the voice. Why they need to treat disrespectful, why they need to bear the discrimination, for a WBC if, without structural changes, they may suffer in a triple way, the illness itself, the discrimination caused by the cancer stigma, and no chance to be given to say goodbye to the beloved that is the triple suffering and as triple oppressions.

\section{References}

Gilligan, C. (1982). In a Different Voice: Psychological Theory and Women's Development. Cambridge, Massachusetts: Harvard University Press

J.S. Simpson, L.E. Carlson, C.A. Beck, et al. (2002). Effects of a brief intervention on social support and psychiatric morbidity in breast cancer patients. Psycho-Oncology, 11 (4), 282-294

Kim, H. S., \& Kollak, I. (Eds.) (2006). Nursing theories: Conceptual and philosophical foundations (2nd ed.). New York: Springer Publishing Company.

Mertler, C. A. (2017). Action research: Improving schools and empowering educators. Thousand Oaks, CA: Sage Publications.

Nandu.com. (2014). Q̄ī chéng shòu făng zhě bù zhīdào shénme shì yīwù shèhuì gōngzuò. Southern Metropolis Daily. Retrieved $16^{\text {th }}$ June from http://news.ifeng.com/ gundong/detail_2014_03/21/34992506_0.shtml

Schilder, P. (1950). The imäge and appearance of the human body. New York: International University Press.

Stang, I., \& Mittelmark, M. (2009). Learning as an empowerment process in breast cancer self-help groups. Journal of Clinical Nursing, 18(14), 2049-2057.

Walker, A. J., \& Thompson, L. (1983). Intimacy and intergenerational aid and contact among mothers and daughters. Journal of Marriage and the Family, 45, 841-849.

Wang, F., Liu, J., Liu, L., Wang, F., Ma, Z., Gao, D., Zhang, Q., \& Yu, Z. (2014). The status and correlates of depression and anxiety among breast-cancer survivors in Eastern China: A population-based, cross-sectional case-control study. BMC Public Health, 14, 326. https://doi.org/10.1186/1471-2458-14-326.

Woloski-Wruble, A., \& Kadmon, I. (2002). Breast cancer: Reactions of Israeli men to their wives' diagnosis. European Journal of Oncology Nursing, 6(2), 93-99.

Yang, J. (2003). Fantastic costume: The female breast cancer patients, gender performance, and body image. Taiwan: A Radical Quarterly in Social Studies, 49-95.

Yusuf, A., Ab Hadi, I., Mahamood, Z., Ahmad, Z., \& Keng, S. (2013). Understanding the breast cancer experience: A qualitative study of Malaysian women. Asian Pacific Journal of Cancer Prevention, 14(6), 3689-3698. 